\title{
REST AND SOAP COMPARISON ON WEB SERVICE TECHNOLOGY FOR ANDROID BASED DATA SERVICES
}

\author{
Anggraini Kusumaningrum ${ }^{1)}$, Haruno Sajati ${ }^{2)}$, Donny Anarianto ${ }^{3)}$ \\ ${ }^{1,2,3)}$, Departemen Informatika, Sekolah Tinggi Teknologi Adisutjipto \\ Jl. Janti Blok R, Lanud Adisutjipto Yogyakarta 55198 \\ Email : ${ }^{1}$ anggraini@stta.ac.id, ${ }^{2}$ haruno@stta.ac.id, ${ }^{3}$ donnypurwanto36@gmail.com
}

\begin{abstract}
Comparison between ReST API and SOAP web services in providing data services that are carried out to support the improvement of these web services. The data tested is divided into 2, namely data with the same size format and data with different size formats. The test is divided into 3 stages, the first collecting with 10 data, the second 20 data, and the third 30 data, by carrying out data loading from each comparing web service. From the overall results obtained from the ReST API runs faster than SOAP. With an overall total data collection time on different devices with the same size format in the ReST API it produces 3.4 seconds and SOAP produces 3.9 seconds. While receiving data on different devices with different size formats on the ReST API, it takes 4.7 seconds and SOAP takes 5.3 seconds.
\end{abstract}

Keywords: Web service, SOAP, ReST API

\section{Pendahuluan}

ReST merupakan suatu arsitektur metode komunikasi yang menggunakan protokol Hyper Text Transfer Protocol (HTTP) untuk pertukaran data dan metode ini sering diterapkan dalam pengembangan aplikasi. ReST sendiri memungkinkan system request dapat mengakses dan memanipulasi teks yang direpresentasikan dari sebuah web service. Web service API yang menggunakan ReST disebut dengan ReSTful API. Tidak seperti jenis web service lainnya, ReSTful API tidak memiliki standar yang resmi untuk notasinya dikarenakan ReST merupakan sebuah arsitektur. SOAP merupakan arsitektur standar untuk melakukan pertukaran data atau pesan-pesan berbasis XML melalui jaringan komputer untuk melakukan komunikasi dengan program pada platform yang sama ataupun berbeda menggunakan HTTP dan XML sebagai mekanisme pertukaran data. SOAP meliputi tiga bagian utama yaitu tipe informasi yang akan dikirim, bagaimana. Beberapa penelitian yang membahas tentang webservice diantaranya sebagai berikut, penelitian tentang Web Service For Supporting Of Website Performance bertujuan membangun web service agar dapat mendukung kinerja website[1]. Comparative Analysis Of Xml And Json Using Php Application Platform With Representational State Transfer (ReST) Architectural bertujuan untuk untuk menganalisis perbandingan waktu serialisasi data, waktu parsing data dan ukuran data XML dan JSON sebagai format pertukaran data dengan arsitektur ReST [2]. Pemanfaatan Teknologi Web Service Untuk Integrasi Sistem Layanan Materi Pelajaran Terdistribusi bertujuan untuk merancang dan membangun suatu integrasi sistem layanan materi pelajaran antar sekolah menggunakan web service dalam mendistribusikan datanya ke pengguna dengan berbagai kebutuhan [3]. penelitiannya yang berjudul Implementasi ReST API pada Aplikasi Panduan Kepaskibraan Berbasis Android bertujuan untuk menggunakan ReST API dalam pembuatan Aplikasi Panduan Kepaskibraan dan dengan adanya dukungan notasi JSON [4]. Pencarian Content Portal Web Berita Dengan Teknik Sindikasi Berbasis Ajax-Soap Web Service yaitu bertujuan untuk mempermudah dalam pencarian content [5]. 


\section{Metodologi Penelitian}

Teknologi Web service dapat diimplementasikan dengan SOAP (Simple Object Access Protocol) atau ReST (Representational State Transfer). Walaupun memiliki kesamaan dalam pertukaran data dengan berkomunikasi melalui web service, namun tetap memiliki beberapa hal yang berbeda. Pada Tabel 1 merupakan perbedaan ReST API dan SOAP.

\section{Tabel 1 Perbedaan ReST API dan SOAP}

(Sumber : Wisnu, N, 2012)

\begin{tabular}{|c|c|c|}
\hline Uraian & ReST & SOAP \\
\hline $\begin{array}{l}\text { Protokol } \\
\text { komunikasi }\end{array}$ & HTTP, HTTPS & HTTP, HTTPS, SMTP, FTP \\
\hline $\begin{array}{l}\text { Penggunaan } \\
\text { bandwidth }\end{array}$ & $\begin{array}{l}\text { Relatif hemat bandwidth, karena } \\
\text { markup-markup ekstra seperti pada } \\
\text { XML tidak dipakai }\end{array}$ & $\begin{array}{l}\text { Dalam jumlah request yang banyak, relatif boros } \\
\text { bandwidth. Hal ini karena banyaknya markup } \\
\text { dalam penulisan format XML }\end{array}$ \\
\hline $\begin{array}{l}\text { Tren } \\
\text { penggunaan }\end{array}$ & $\begin{array}{l}\text { Mulai populer, banyak dipakai oleh } \\
\text { penyedia web servis terkemuka, } \\
\text { seperti twitter, yahoo!, } \\
\text { flickr,bloglines, technorati, google, } \\
\text { amazon, eBay, dan sebagainya }\end{array}$ & $\begin{array}{l}\text { Banyak mulai beralih ke REST, meski masih } \\
\text { tetap ada yang mempertahankan, misalnya untuk } \\
\text { integrasi aplikasi ke sistem legasi pada sebuah } \\
\text { perusahaan. }\end{array}$ \\
\hline $\begin{array}{l}\text { Aturan } \\
\text { penulisan }\end{array}$ & Tidak ada spesifikasi khusus & Ketat, mengikuti spesifikasi XML (SOAP v1.2) \\
\hline Format respon & $\begin{array}{l}\text { XML, JSON, atau format plain teks } \\
\text { lainnya. Hal ini memudahkan } \\
\text { penerima respon membaca dan } \\
\text { memahaminya. }\end{array}$ & $\begin{array}{l}\text { XML dengan spesifikasi SOAP. Agak sulit } \\
\text { untuk membaca langsung dan memahaminya. }\end{array}$ \\
\hline $\begin{array}{l}\text { Attachment } \\
\text { file }\end{array}$ & Tidak Bisa & $\begin{array}{l}\text { Bisa (karena dapat mengembalikan respon } \\
\text { dalam format binary) }\end{array}$ \\
\hline $\begin{array}{l}\text { Sifat web } \\
\text { servis pada } \\
\text { umumnya }\end{array}$ & $\begin{array}{l}\text { Terbuka, bisa diakses siapa saja (web } \\
\text { API) }\end{array}$ & $\begin{array}{l}\text { Tertutup, lebih ditujukan untuk vendor atau } \\
\text { perusahaan tertent }\end{array}$ \\
\hline Caching web & Mudah, karena menggunakan URI & Relatif sulit \\
\hline $\begin{array}{l}\text { Penggunaan } \\
\text { standar }\end{array}$ & $\begin{array}{l}\text { Standar yang sudah ada, seperti } \\
\text { XML dan HTTP }\end{array}$ & $\begin{array}{l}\text { Standar lama (XML, HTTP) dan baru .(SOAP) } \\
\text { digunakan bersamaan }\end{array}$ \\
\hline $\begin{array}{l}\text { Tool } \\
\text { pengembangan }\end{array}$ & $\begin{array}{l}\text { Beberapa, karena tidak begitu } \\
\text { dibutuhkan }\end{array}$ & $\begin{array}{llll}\begin{array}{l}\text { Banyak, baik } \\
\text { opensource }\end{array} & \text { komersial maupun } \\
\end{array}$ \\
\hline $\begin{array}{l}\text { Tool } \\
\text { manajemen }\end{array}$ & $\begin{array}{l}\text { Menggunakan tool yang sudah ada } \\
\text { pada sistem jaringan }\end{array}$ & Perlu, bahkan kadang harganya mahal \\
\hline Ekstensibel & Relatif tidak ekstensibel & Bisa, banyak ekstensi termasuk standar WS \\
\hline $\begin{array}{l}\text { Kemudahan } \\
\text { implementasi }\end{array}$ & Mudah & $\begin{array}{l}\text { Mudah jika sudah memiliki lingkungan berbasis } \\
\text { SOAP }\end{array}$ \\
\hline
\end{tabular}

API memungkinkan developer untuk mengintegrasikan dua bagian dari aplikasi atau dengan aplikasi yang berbeda secara bersamaan. API terdiri dari berbagai elemen seperti function, protocols, dan tools lainnya yang memungkinkan developers untuk membuat aplikasi sedagkan SOAP adalah standar untuk melakukan pertukaran pesan-pesan berbasis $X M L$ melalui jaringan komputer 


\subsection{Perancangan Web Service}

Terdapat dua teknologi web service yang dirancang yaitu web service ReST API dan SOAP. Kedua teknologi web service ini akan dibandingkan dalam performa menyediakan data dengan aplikasi client. Jenis data yang akan dibandingkan berupa data artikel baca yaitu gambar dan teks. Untuk dapat berkomunikasi client-server membutuhkan koneksi internet agar aplikasi client bisa melakukan request ke server dan menerima respon dari server. Web service ReST API dan SOAP mempunyai fungsi menyediakan layanan terhadap aplikasi kepada client berupa data artikel. Untuk representasi data, web service ReST API menyediakan layanan datanya dalam bentuk format JSON. Sedangkan untuk representasi data web service SOAP menyediakan layanan datanya dalam bentuk format XML. Gambar 1 merupakan arsitektur komunikasi antara Client - Server.

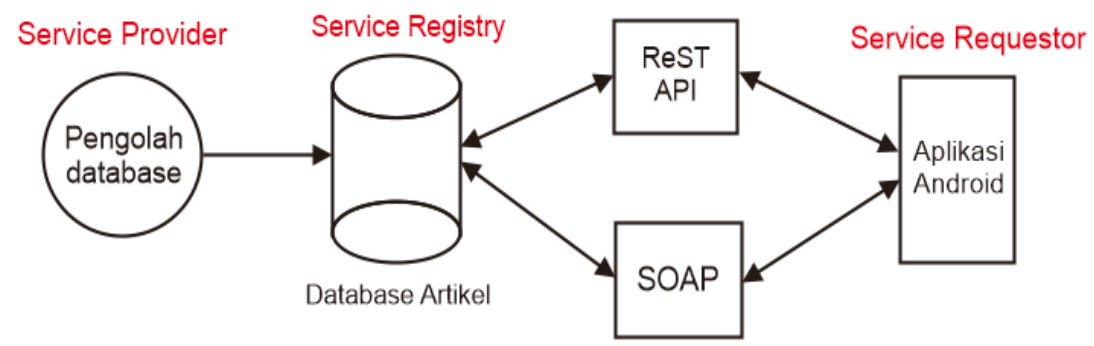

Gambar 1 Komunikasi Antara Client-Server

\subsection{Perancangan web service ReST API}

Web service ReST API berfungsi untuk menyediakan data yang diminta oleh aplikasi client. Sebelum menyediakan data yang diminta oleh aplikasi client, ReST API terlebih dahulu menghubungi server dalam hal ini yaitu MySQL database. Maka dari itu web service ReST API di sini bertindak sebagai jembatan antara peminta layanan dengan penyedia layanan (database). Web service ReST API menampilkan datanya dalam format JSON untuk menyediakan data yang dibutuhkan aplikasi client. Agar bisa menyediakan layanan data yang dibutuhkan client, web service ReST API harus terhubung ke dalam jaringan internet. Gambar 2 merupakan Deskripsi Sistem ReST API Secara Umum dan Gambar 3 merupakan Skema Komunikasi Web Service ReST API.

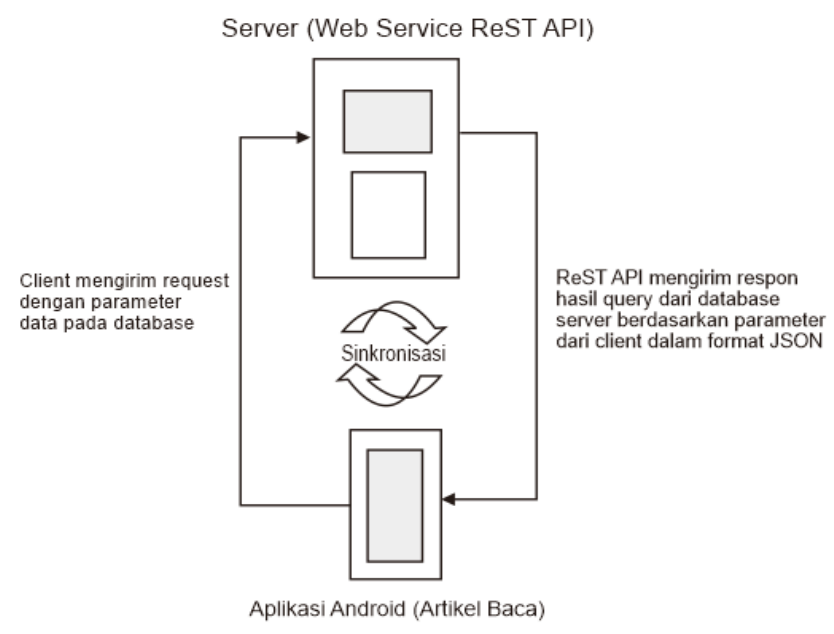

Gambar 2. Deskripsi Sistem ReST API Secara Umum 


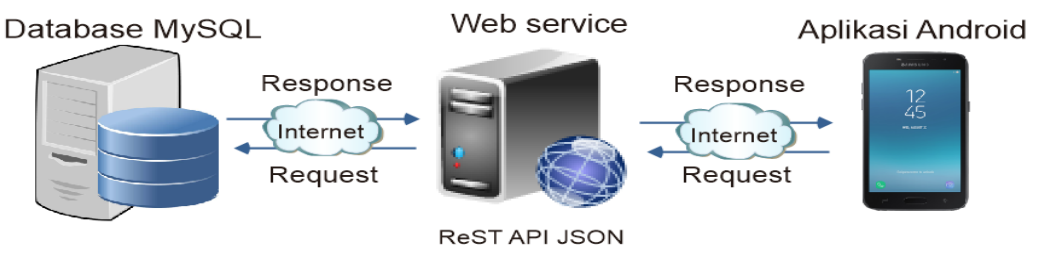

Gambar 3. Skema Komunikasi Web Service ReST API

\subsection{Perancangan web service SOAP}

web service SOAP juga memberikan layanan web service untuk menyediakan data yang diminta oleh aplikasi client. Namun dalam menyediakan data web service SOAP berbeda dengan ReST API. Web service SOAP menggunakan bahasa XML sebagai web service sedangkan ReST API menggunakan bahasa JSON. Untuk memberikan layanan web service, SOAP tidak langsung mengakses database MySQL. SOAP service terlebih dahulu menghubungi server SOAP, kemudian setelah server mengecek ketersediaan data yang diminta, server akan menghubungi client SOAP untuk melakukan verifikasi data. Setelah client SOAP menerima data dan sudah melakukan verifikasi data dari server SOAP, baru kemudian akan ditampilkan di dalam service SOAP XML. Kemudian data di dalam service SOAP XML diparsing dan ditampilkan pada aplikasi client. Agar bisa menyediakan layanan data yang dibutuhkan client, web service ReST API harus terhubung ke dalam jaringan internet. Gambar 4 Deskripsi Sistem SOAP Secara Umum dan Gambar 5 Skema Komunikasi Web Service SOAP.

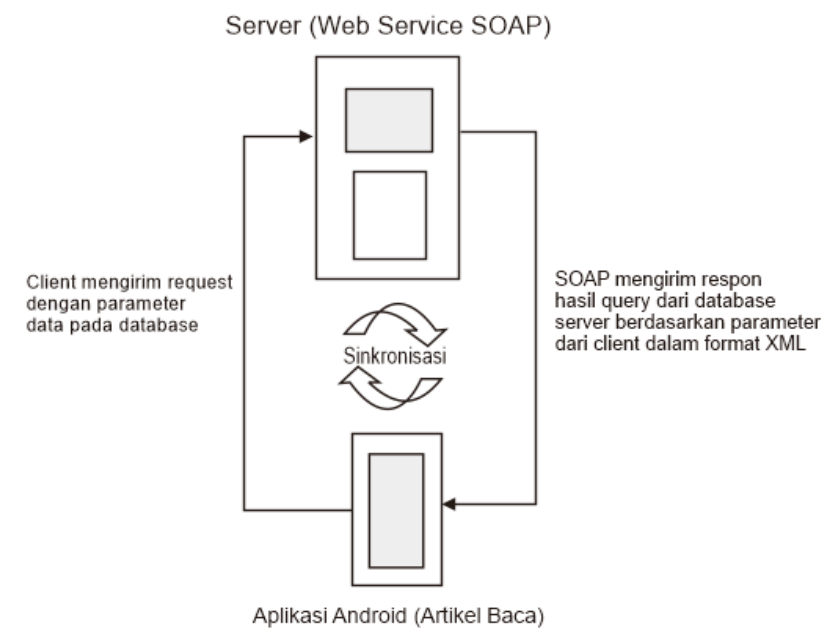

Gambar 4. Deskripsi Sistem SOAP Secara Umum

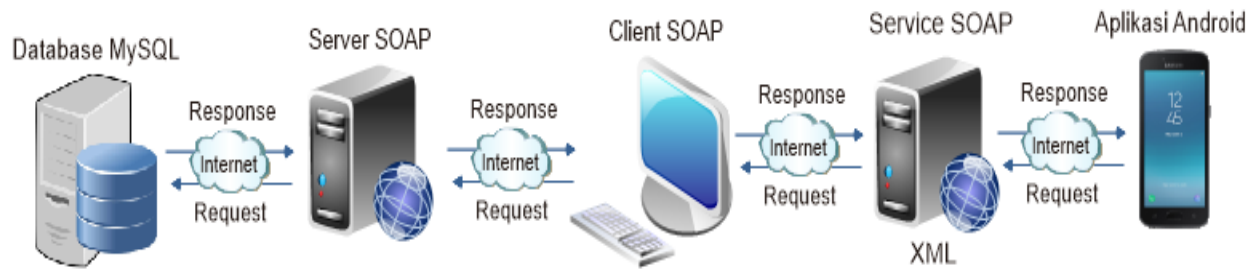

Gambar 5. Skema Komunikasi Web Service SOAP 


\subsection{Use Case Diagram}

Gambar 6 merupakan Use Case Diagram pada aplikasi client berbasis Android yang menjelaskan bahwa saat user membuka aplikasi diberikan pilihan ingin melihat data ReST API atau SOAP. Setelah melakukan pilihan maka akan ditampilkan data yang sesuai dengan pilihan user.

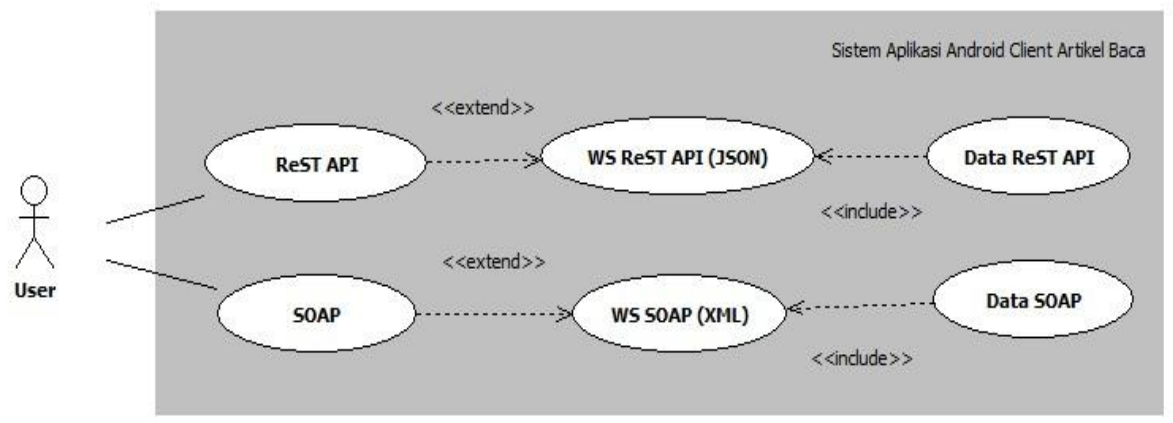

Gambar 6. Use Case Diagram pada Aplikasi Android

\subsection{Perancangan Database}

Dalam pertukaran data antara web service ReST API dan SOAP dengan aplikasi client Android dibutuhkan 1tabel dalam database. Tabel ini digunakan untuk menyimpan data yang telah diinput. Di dalam tabel ini semua data yang telah diinput akan disimpan. Detail tabel dapat dilihat pada Tabel 2.

Tabel 2. Tabel data

\begin{tabular}{|c|c|c|c|}
\hline Field & Size & Type & Primary Key \\
\hline id_artikel & 11 & int & Primary Key \\
\hline judul_artikel & 100 & varchar & \\
\hline isi_artikel & & longtext & \\
\hline penulis_artikel & 250 & varchar & \\
\hline photo_artikel & 250 & varchar & \\
\hline tgl_artikel & & timestamp & \\
\hline
\end{tabular}

\section{Hasil dan Pembahasan}

Pengujian sistem ini terdiri dari dua bagian yaitu fungsi pertama aplikasi yaitu menampilkan data dari web service ReST API dan web service SOAP pada beberapa perangkat Android. Untuk fungsi ke dua yaitu melakukan perbandingan performansi lama waktu memuat data dari web service ReST API dan web service SOAP.

\subsection{Pengujian Aplikasi Client pada Perangkat Android}

Pengujian ini dilakukan untuk mengetahui apakah aplikasi Android ini berjalan dengan baik diberbagai tipe perangkat Android dengan spesifikasi smartphone yang berbeda-beda. Hasil pengujian dapat dilihat pada Tabel 3. Dari hasil pengujian pada perangkat Android berbeda diperoleh hasil bahwa aplikasi client Android artikel baca dapat berjalan dengan lancar atau berhasil pada beberapa tipe smartphone Android, dengan sistem Android yang berbeda mulai dari versi Lollipop sampai versi Oreo. 
Tabel 3. Pengujian Pada Perangkat Android

\begin{tabular}{|c|c|c|c|c|c|c|}
\hline No & Nama Smartphone & Processor & RAM & $\begin{array}{c}\text { Memori } \\
\text { Internal }\end{array}$ & Versi Android & $\begin{array}{c}\text { Respon } \\
\text { Aplikasi } \\
\text { Android }\end{array}$ \\
\hline 1 & Sony Z2 Compact & Qualcomm Snapdragon 800 & $2 \mathrm{~GB}$ & $16 \mathrm{~GB}$ & Lollipop 5.0.1 & Berhasil \\
\hline 2 & Xiaomi Redmi Note 3 & Qualcomm Snapdragon 800 & $3 \mathrm{~GB}$ & $32 \mathrm{~GB}$ & Lollipop 5.1.1 & Berhasil \\
\hline 3 & Sony Z4 Compact & Qualcomm Snapdragon 801 & $2 \mathrm{~GB}$ & $16 \mathrm{~GB}$ & $\begin{array}{c}\text { Marsmallow } \\
6.0 .1\end{array}$ & Berhasil \\
\hline 4 & Oppo A71 & Mediatek MT6750 & $2 \mathrm{~GB}$ & $16 \mathrm{~GB}$ & Nougat 7.1.1 & Berhasil \\
\hline 5 & Xiaomi Redmi 4X & Qualcomm Snapdragon 435 & $2 \mathrm{~GB}$ & $16 \mathrm{~GB}$ & Nougat 7.1.2 & Berhasil \\
\hline 6 & Xiaomi Redmi Note 5 Pro & Qualcomm Snapdragon 636 & $4 \mathrm{~GB}$ & $64 \mathrm{~GB}$ & Oreo 8.1.0 & Berhasil \\
\hline 7 & Asus Zenfone 4 Max & ARM Cortex-A53 & $3 \mathrm{~GB}$ & $32 \mathrm{~GB}$ & Oreo 8.1.0 & Berhasil \\
\hline
\end{tabular}

\subsection{Pengujian Web Service ReST API dan SOAP}

Pengujian ini dilakukan pada perangkat dengan spesifikasi yang berbeda dan memiliki versi Android yang berbeda. Langkah pengujian dilakukan dengan cara menghitung waktu lama aplikasi client memuat data dari web service ReST API dan web service SOAP. Pengujian dilakukan sebanyak 5 kali pada setiap web service, dengan cara scroll data dari atas sampai bawah, hingga semua data berupa data gambar dan teks tampil. Adapun tabel data spesifikasi device Android yang digunakan dalam uji coba dapat dilihat pada Tabel 4.

Tabel 4. Spesifikasi Perangkat yang Diujikan

\begin{tabular}{|c|c|c|c|c|c|}
\hline No & Nama Smartphone & Processor & RAM & $\begin{array}{c}\text { Memori } \\
\text { Internal }\end{array}$ & Versi Android \\
\hline A & Sony Z4 Compact & Qualcomm Snapdragon 801 & $2 \mathrm{~GB}$ & $16 \mathrm{~GB}$ & $\begin{array}{c}\text { Marsmallow } \\
6.0 .1\end{array}$ \\
\hline B & Asus Zenfone 4 Max & ARM Cortex-A53 & $3 \mathrm{~GB}$ & $32 \mathrm{~GB}$ & Oreo 8.1.0 \\
\hline C & Xiaomi Redmi Note 5 Pro & Qualcomm Snapdragon 636 & $4 \mathrm{~GB}$ & $64 \mathrm{~GB}$ & Oreo 8.1.0 \\
\hline
\end{tabular}

\subsection{Pengujian pada Perangkat A}

Pengujian ini dilakukan pada perangkat smartphone Sony Z4 Compact dengan versi Android Marsmallow 6.0.1, RAM 2GB Internal 16GB. Pengujian dilakukan sebanyak dua kali, yang pertama pengujian pada ukuran format data gambar dan teks semua sama. Yang ke dua pengujian pada ukuran format data gambar dan teks semua berbeda-beda. Adapun hasil pengujian pada perangkat A sebagai berikut. Pengujian pada ukuran format gambar dan teks semua sama. Untuk hasil pengujian data gambar dan teks yang sama dapat dilihat pada Tabel 5 dan hasil pengujian data gambar dan teks yang berbeda dapat dilihat pada Tabel 6. 
Tabel 5. Pengujian Perangkat A Format Ukuran Data Sama

\begin{tabular}{|c|c|c|c|c|c|c|c|}
\hline \multirow{2}{*}{$\begin{array}{l}\text { Jumlah } \\
\text { Data }\end{array}$} & \multicolumn{2}{|c|}{ Ukuran File } & \multicolumn{3}{|c|}{$\begin{array}{l}\text { Waktu Sinkronisasi } \\
\text { Data (Detik) }\end{array}$} & \multicolumn{2}{|c|}{$\begin{array}{l}\text { Rata-Rata Waktu } \\
\text { Sinkronisasi Data } \\
\text { (Detik) }\end{array}$} \\
\hline & $\begin{array}{c}\text { ReST API } \\
\text { (JSON) }\end{array}$ & $\begin{array}{l}\text { SOAP } \\
\text { (XML) }\end{array}$ & $\begin{array}{c}\text { Uji } \\
\text { Coba }\end{array}$ & $\begin{array}{c}\text { ReST } \\
\text { API }\end{array}$ & SOAP & $\begin{array}{c}\text { ReST } \\
\text { API }\end{array}$ & SOAP \\
\hline \multirow{5}{*}{10} & \multirow{5}{*}{$18.64 \mathrm{~KB}$} & \multirow{5}{*}{$18.66 \mathrm{~KB}$} & $\mathrm{I}$ & 2.1 & 2.7 & \multirow{5}{*}{2.3} & \multirow{5}{*}{2.7} \\
\hline & & & II & 2.5 & 2.8 & & \\
\hline & & & III & 2.3 & 2.5 & & \\
\hline & & & IV & 2.6 & 2.9 & & \\
\hline & & & $\mathrm{V}$ & 2.2 & 2.4 & & \\
\hline \multirow{5}{*}{20} & \multirow{5}{*}{$37.02 \mathrm{~KB}$} & \multirow{5}{*}{$37.01 \mathrm{~KB}$} & $\mathrm{I}$ & 3.9 & 4.1 & \multirow{5}{*}{3.9} & \multirow{5}{*}{4} \\
\hline & & & II & 3.8 & 3.9 & & \\
\hline & & & III & 3.9 & 4.2 & & \\
\hline & & & IV & 4 & 4.2 & & \\
\hline & & & $\mathrm{V}$ & 3.9 & 3.9 & & \\
\hline \multirow{5}{*}{30} & \multirow{5}{*}{$55.42 \mathrm{~KB}$} & \multirow{5}{*}{$55.37 \mathrm{~KB}$} & $\mathrm{I}$ & 4.9 & 5.6 & \multirow{5}{*}{4.6} & \multirow{5}{*}{5.1} \\
\hline & & & II & 4.5 & 4.9 & & \\
\hline & & & III & 4.8 & 5.1 & & \\
\hline & & & IV & 4.5 & 5 & & \\
\hline & & & $\mathrm{V}$ & 4.5 & 5.1 & & \\
\hline
\end{tabular}

Tabel 6. Pengujian Perangkat A Format Ukuran Data Berbeda

\begin{tabular}{|c|c|c|c|c|c|c|c|}
\hline \multirow{2}{*}{$\begin{array}{c}\text { Jumlah } \\
\text { Data }\end{array}$} & \multicolumn{2}{|c|}{ Ukuran File } & \multicolumn{3}{|c|}{$\begin{array}{c}\text { Waktu Sinkronisasi Data } \\
\text { (Detik) }\end{array}$} & \multicolumn{2}{|c|}{$\begin{array}{l}\text { Rata-Rata Waktu } \\
\text { Sinkronisasi Data } \\
\text { (Detik) }\end{array}$} \\
\hline & $\begin{array}{c}\text { ReST API } \\
\text { (JSON) }\end{array}$ & $\begin{array}{l}\text { SOAP } \\
\text { (XML) }\end{array}$ & $\begin{array}{c}\text { Uji } \\
\text { Coba }\end{array}$ & $\begin{array}{c}\text { ReST } \\
\text { API }\end{array}$ & SOAP & $\begin{array}{c}\text { ReST } \\
\text { API }\end{array}$ & SOAP \\
\hline \multirow{5}{*}{10} & \multirow{5}{*}{$11.48 \mathrm{~KB}$} & \multirow{5}{*}{$11.28 \mathrm{~KB}$} & I & 2.8 & 3.1 & \multirow{5}{*}{2.4} & \multirow{5}{*}{2.6} \\
\hline & & & II & 2.5 & 2.6 & & \\
\hline & & & III & 2.1 & 2.3 & & \\
\hline & & & IV & 2.1 & 2.4 & & \\
\hline & & & V & 2.3 & 2.8 & & \\
\hline \multirow{5}{*}{20} & \multirow{5}{*}{$22.81 \mathrm{~KB}$} & \multirow{5}{*}{$22.38 \mathrm{~KB}$} & $\mathrm{I}$ & 3.3 & 4 & \multirow{5}{*}{3.6} & \multirow{5}{*}{4.1} \\
\hline & & & II & 3.9 & 4.4 & & \\
\hline & & & III & 3.6 & 4 & & \\
\hline & & & IV & 3.8 & 3.9 & & \\
\hline & & & V & 3.4 & 4.2 & & \\
\hline 30 & $33.86 \mathrm{~KB}$ & $33.14 \mathrm{~KB}$ & I & 5.8 & 7.7 & 7.6 & 8.7 \\
\hline
\end{tabular}

\subsection{Pengujian pada Perangkat $B$}

Pengujian ini dilakukan pada perangkat smartphone Asus Zenfone 4 Max dengan versi Android Oreo 8.1.1, RAM 3GB Internal 32GB. Pengujian dilakukan sebanyak dua kali, yang pertama pengujian pada ukuran format data gambar dan teks semua sama. Yang ke dua pengujian pada ukuran format data gambar dan teks semua berbeda-beda. Adapun hasil 
pengujian pada perangkat B sebagai berikut. Pengujian pada ukuran format gambar dan teks semua sama. Untuk hasil pengujian data gambar dan teks yang sama dapat dilihat pada Tabel 7 dan pengujian data gambar dan teks yang berbeda dapat dilihat pada Tabel 8 .

Tabel 7.Pengujian Perangkat B Format Ukuran Data Sama

\begin{tabular}{|c|c|c|c|c|c|c|c|}
\hline \multirow{2}{*}{$\begin{array}{c}\text { Jumlah } \\
\text { Data }\end{array}$} & \multicolumn{2}{|c|}{ Ukuran File } & \multicolumn{3}{|c|}{$\begin{array}{c}\text { Waktu Sinkronisasi Data } \\
\text { (Detik) }\end{array}$} & \multicolumn{2}{|c|}{$\begin{array}{l}\text { Rata-Rata Waktu } \\
\text { Sinkronisasi Data } \\
\text { (Detik) }\end{array}$} \\
\hline & $\begin{array}{l}\text { ReST API } \\
(\text { JSON) }\end{array}$ & $\begin{array}{l}\text { SOAP } \\
\text { (XML) }\end{array}$ & $\underset{\text { Coba }}{\text { Uji }}$ & $\begin{array}{c}\text { ReST } \\
\text { API }\end{array}$ & SOAP & $\begin{array}{c}\text { ReST } \\
\text { API }\end{array}$ & SOAP \\
\hline \multirow{5}{*}{10} & \multirow{5}{*}{$18.64 \mathrm{~KB}$} & \multirow{5}{*}{$18.66 \mathrm{~KB}$} & $\mathrm{I}$ & 2.8 & 3.5 & \multirow{5}{*}{2.4} & \multirow{5}{*}{3} \\
\hline & & & II & 2.3 & 2.7 & & \\
\hline & & & III & 2.4 & 2.9 & & \\
\hline & & & IV & 2.4 & 2.8 & & \\
\hline & & & $\mathrm{V}$ & 2.3 & 2.7 & & \\
\hline \multirow{5}{*}{20} & \multirow{5}{*}{$37.02 \mathrm{~KB}$} & \multirow{5}{*}{$37.01 \mathrm{~KB}$} & $\mathrm{I}$ & 3.4 & 4.2 & \multirow{5}{*}{3.4} & \multirow{5}{*}{3.9} \\
\hline & & & II & 3.6 & 4.1 & & \\
\hline & & & III & 3.6 & 3.8 & & \\
\hline & & & IV & 3.4 & 3.9 & & \\
\hline & & & $\mathrm{V}$ & 3.2 & 3.5 & & \\
\hline \multirow{5}{*}{30} & \multirow{5}{*}{$55.42 \mathrm{~KB}$} & \multirow{5}{*}{$55.37 \mathrm{~KB}$} & I & 4.5 & 5.7 & \multirow{5}{*}{4.7} & \multirow{5}{*}{5.3} \\
\hline & & & II & 4.9 & 5.4 & & \\
\hline & & & III & 4.9 & 5.2 & & \\
\hline & & & IV & 4.4 & 5 & & \\
\hline & & & $\mathrm{V}$ & 4.8 & 5.1 & & \\
\hline
\end{tabular}

Tabel 8. Pengujian Perangkat B Format Ukuran Data Berbeda

\begin{tabular}{|c|c|c|c|c|c|c|c|}
\hline \multirow{2}{*}{$\underset{\text { Data }}{\text { Jumlah }}$} & \multicolumn{2}{|c|}{ Ukuran File } & \multicolumn{3}{|c|}{$\begin{array}{c}\text { Waktu Sinkronisasi Data } \\
\text { (Detik) }\end{array}$} & \multicolumn{2}{|c|}{$\begin{array}{l}\text { Rata-Rata Waktu } \\
\text { Sinkronisasi Data } \\
\text { (Detik) }\end{array}$} \\
\hline & $\begin{array}{l}\text { ReST API } \\
\text { (JSON) }\end{array}$ & $\begin{array}{l}\text { SOAP } \\
\text { (XML) }\end{array}$ & $\begin{array}{c}\text { Uji } \\
\text { Coba }\end{array}$ & $\begin{array}{c}\text { ReST } \\
\text { API }\end{array}$ & SOAP & $\begin{array}{c}\text { ReST } \\
\text { API }\end{array}$ & SOAP \\
\hline \multirow{5}{*}{10} & \multirow{5}{*}{$11.48 \mathrm{~KB}$} & \multirow{5}{*}{$11.28 \mathrm{~KB}$} & I & 2.5 & 3 & \multirow{5}{*}{2.4} & \multirow{5}{*}{2.8} \\
\hline & & & II & 2.4 & 2.7 & & \\
\hline & & & III & 2.5 & 2.6 & & \\
\hline & & & IV & 2.3 & 2.5 & & \\
\hline & & & $\mathrm{V}$ & 2.6 & 3.1 & & \\
\hline \multirow{5}{*}{20} & \multirow{5}{*}{$22.81 \mathrm{~KB}$} & \multirow{5}{*}{$22.38 \mathrm{~KB}$} & I & 3.7 & 3.8 & \multirow{5}{*}{3.5} & \multirow{5}{*}{3.8} \\
\hline & & & II & 3.4 & 3.9 & & \\
\hline & & & III & 3.6 & 4 & & \\
\hline & & & IV & 3.8 & 3.9 & & \\
\hline & & & V & 3 & 3.5 & & \\
\hline 30 & $33.86 \mathrm{~KB}$ & $33.14 \mathrm{~KB}$ & I & 8.2 & 9 & 8.3 & 9.2 \\
\hline
\end{tabular}

\subsection{Pengujian Pada Perangkat $\mathrm{C}$}

Pengujian ini dilakukan pada perangkat smartphone Xiaomi Redmi Note 5 dengan versi 
Android Oreo 8.1.1, RAM 4GB Internal 64GB. Pengujian dilakukan sebanyak dua kali, yang pertama pengujian pada ukuran format data gambar dan teks semua sama. Yang ke dua pengujian pada ukuran format data gambar dan teks semua berbeda-beda. Adapun hasil pengujian pada perangkat $C$ sebagai berikut. Pengujian pada ukuran format gambar dan teks semua sama. Untuk hasil pengujian data gambar dan teks yang sama dapat dilihat pada Tabel 9 dan pengujian data gambar dan teks yang berbeda dapat dilihat pada Tabel 10.

Tabel 9. Pengujian Perangkat C Format Ukuran Data Sama

\begin{tabular}{|c|c|c|c|c|c|c|c|}
\hline \multirow{2}{*}{$\begin{array}{c}\text { Jumlah } \\
\text { Data }\end{array}$} & \multicolumn{2}{|c|}{ Ukuran File } & \multicolumn{3}{|c|}{$\begin{array}{l}\text { Waktu Sinkronisasi Data } \\
\text { (Detik) }\end{array}$} & \multicolumn{2}{|c|}{$\begin{array}{l}\text { Rata-Rata Waktu } \\
\text { Sinkronisasi Data } \\
\text { (Detik) }\end{array}$} \\
\hline & $\begin{array}{c}\text { ReST API } \\
\text { (JSON) }\end{array}$ & $\begin{array}{l}\text { SOAP } \\
\text { (XML) }\end{array}$ & $\begin{array}{c}\text { Uji } \\
\text { Coba }\end{array}$ & $\begin{array}{c}\text { ReST } \\
\text { API }\end{array}$ & SOAP & $\begin{array}{c}\text { ReST } \\
\text { API }\end{array}$ & SOAP \\
\hline \multirow{5}{*}{10} & \multirow{5}{*}{$18.64 \mathrm{~KB}$} & \multirow{5}{*}{$18.66 \mathrm{~KB}$} & I & 2.2 & 2.8 & \multirow{5}{*}{1.8} & \multirow{5}{*}{2.5} \\
\hline & & & II & 1.3 & 2.7 & & \\
\hline & & & III & 1.8 & 2.7 & & \\
\hline & & & IV & 1.7 & 2.2 & & \\
\hline & & & $\mathrm{V}$ & 2 & 2.1 & & \\
\hline \multirow{5}{*}{20} & \multirow{5}{*}{$37.02 \mathrm{~KB}$} & \multirow{5}{*}{$37.01 \mathrm{~KB}$} & $\mathrm{I}$ & 3.8 & 3.9 & \multirow{5}{*}{3.4} & \multirow{5}{*}{3.8} \\
\hline & & & II & 3.1 & 3.7 & & \\
\hline & & & III & 3.1 & 3.8 & & \\
\hline & & & IV & 3.6 & 3.7 & & \\
\hline & & & $\mathrm{V}$ & 3.5 & 3.8 & & \\
\hline \multirow{5}{*}{30} & \multirow{5}{*}{$55.42 \mathrm{~KB}$} & \multirow{5}{*}{$55.37 \mathrm{~KB}$} & $\mathrm{I}$ & 4.6 & 5.1 & \multirow{5}{*}{4.4} & \multirow{5}{*}{4.8} \\
\hline & & & II & 4 & 4.3 & & \\
\hline & & & III & 4.2 & 5.1 & & \\
\hline & & & IV & 4.7 & 4.8 & & \\
\hline & & & $\mathrm{V}$ & 4.3 & 4.6 & & \\
\hline
\end{tabular}

Tabel 10. Pengujian Perangkat C Format Ukuran Data Berbeda

\begin{tabular}{|c|c|c|c|c|c|c|c|}
\hline \multirow{2}{*}{$\begin{array}{c}\text { Jumlah } \\
\text { Data }\end{array}$} & \multicolumn{2}{|c|}{ Ukuran File } & \multicolumn{3}{|c|}{$\begin{array}{c}\text { Waktu Sinkronisasi Data } \\
\text { (Detik) }\end{array}$} & \multicolumn{2}{|c|}{$\begin{array}{l}\text { Rata-Rata Waktu } \\
\text { Sinkronisasi Data } \\
\text { (Detik) }\end{array}$} \\
\hline & $\begin{array}{c}\text { ReST API } \\
\text { (JSON) }\end{array}$ & $\begin{array}{l}\text { SOAP } \\
\text { (XML) }\end{array}$ & $\begin{array}{c}\text { Uji } \\
\text { Coba }\end{array}$ & $\begin{array}{c}\text { ReST } \\
\text { API }\end{array}$ & SOAP & $\begin{array}{c}\text { ReST } \\
\text { API }\end{array}$ & SOAP \\
\hline \multirow{5}{*}{10} & \multirow{5}{*}{$11.48 \mathrm{~KB}$} & \multirow{5}{*}{$11.28 \mathrm{~KB}$} & I & 2.4 & 3.1 & \multirow{5}{*}{2.4} & \multirow{5}{*}{2.9} \\
\hline & & & II & 2.5 & 2.7 & & \\
\hline & & & III & 2.3 & 2.7 & & \\
\hline & & & IV & 2.4 & 3 & & \\
\hline & & & V & 2.5 & 2.9 & & \\
\hline \multirow{5}{*}{20} & \multirow{5}{*}{$22.81 \mathrm{~KB}$} & \multirow{5}{*}{$22.38 \mathrm{~KB}$} & I & 4.9 & 5.8 & \multirow{5}{*}{5} & \multirow{5}{*}{5.5} \\
\hline & & & II & 5 & 5.5 & & \\
\hline & & & III & 5 & 5.1 & & \\
\hline & & & IV & 4.9 & 5.3 & & \\
\hline & & & $\mathrm{V}$ & 5.2 & 5.7 & & \\
\hline 30 & $33.86 \mathrm{~KB}$ & $33.14 \mathrm{~KB}$ & I & 7.6 & 8 & 7.4 & 7.8 \\
\hline
\end{tabular}




\section{Kesimpulan}

1. Pengujian 30 sampel data dengan jumlah data bervariasi, diuji pada device smartphone yang berbeda, jaringan internet berbeda, dan ukuran file berbeda (ReST API lebih besar ukuran file-nya dan SOAP lebih kecil ukuran file-nya), dihasilkan rata-rata waktu sinkronisasi data ReST API lebih cepat dibandingkan SOAP.

2. Hasil rata-rata keseluruhan sinkronisasi data dengan format ukuran data yang sama pada ReST API menghasilkan waktu 3.4 detik dan SOAP menghasilkan waktu 3.9 detik, sedangkan dengan format ukuran data yang berbeda pada ReST API menghasilkan waktu 4.7 detik dan SOAP menghasilkan waktu 5.3 detik.

\section{Daftar Pustaka}

[1] Sinta, T.P., A. Basukesti, dan D. Nugraheny. 2012. Web Service For Supporting Of Website Performance. Jurnal Compiler 1(2): 89-97.

[2] Saryanto, S., Sumarsono, S., \& Retnowati, N. D. (2013). Comparative Analysis of XML and JSON Using Php Application Platform with Representational State Transfer (Rest) Architectural. Compiler, 2(2).

[3] AyuningTyas, A., \& Ashari, A. (2016). Pemanfaatan Teknologi Web Service Untuk Integrasi Sistem Layanan Materi Pelajaran Terdistribusi. Angkasa: Jurnal Ilmiah Bidang Teknologi, 8(1), 33-46.

[4] Rulloh, A., Mahmudah, D. E., \& Kabetta, H. (2017). Implementasi REST API pada Aplikasi Panduan Kepaskibraan Berbasis Android. Teknikom: Teknologi Informasi, Ilmu Komputer dan Manajemen, 1(2), 85-89.

[5] Suteja, B. R. (2018). Pencarian Content Portal Web Berita Dengan Teknik Sindikasi Berbasis Ajax-Soap Web Service. Compiler, 7(1).

[6] Wisnu, N. 2012. Perbandingan SOAP dan REST sebagai Web Service. http://pusdiklat.bps.go.id/index.php?r=artikel/view\&id=206. 15 Mei 2019 (20.40) 